\title{
TOURISM DESTINATIONS INFORMATION SEEKING AND DISSEMINATION BEHAVIORS ON SOCIAL NETWORKING SITES
}

\author{
Nguyen Minh Dang', Vo Thanh Thao ${ }^{2}$ \\ ${ }^{1}$ Xuan Oanh Trading and Services Limited Liability Company \\ ${ }^{2}$ SaigonTourist College \\ Email: nmdang24@gmail.com
}

(Received:26/05/2015; Revised: 07/08 /2015; Accepted:14/08/2015)

\begin{abstract}
Social networking sites (SNS) are a modern form of communication used by the young people across the world. Many young people discuss on forums and exchange information, opinions on SNS. This study empirically examines the effects of consumer opinion leadership (COL) and consumer susceptibility to interpersonal influence (CSII) on young people's tourism destinations information seeking and dissemination behavior on SNS from consumers' point of view. The study aimed to answer the following questions: Does COL and CSII affect young people's tourism destinations information seeking and dissemination behavior on SNS? Is there gender difference in young people's tourism destinations information seeking and dissemination behavior on SNS? The data generated from various instruments were organized into emerging themes to validate the findings. The results indicated COL and CSII only affected tourism destinations information seeking and dissemination behaviors on SNS of young people. Gender was not supported by the research. These findings suggest that, marketing activities and tactics should be engaged to attract opinion leaders.
\end{abstract}

Keywords: Consumer opinion leadership, consumer susceptibility to interpersonal influence, social Networking Websites.

\section{Introduction}

Since the development of the Internet, social networking sites (SNS) have grown rapidly in popularity. Modern SNS are increasingly used in business, creating new channels for consumers to connect with companies and other customers. Many SNS provide consumers with an opportunity to write reviews of and provide feedback about products and services they used. Young people are the most popular user of SNS. They can find or share information of some destinations they had visited on the SNS. They consult more than friends and relatives when they visited somewhere by turning to online guide and social media. Young consumers are also an important market segment of the tourism. Therefore, this study aims to explore tourist destination information seeking and dissemination behavior of young people with regard to information about SNS to help marketers and researchers understand young consumers and social media marketing more clearly by trying to answer these quesions:

1. Does consumer opinion leadership (COL) affect young people's tourism destinations information seeking and dissemination behavior on SNS?

2. Does consumer susceptibility to interpersonal influence (CSII) affect 
young people's tourism destinations information seeking and dissemination behavior on SNS?

3. Is there gender difference in young people's tourism destinations information seeking and dissemination behavior on SNS?

The trend of using social network sites (SNS) is a globally widespread phenomenon. SNS such as Facebook and Twitter have approximately 465 million, 115 million, and 4 to 5 million global users respectively (Gonzalez et al., 2012). The Report by ComScore shows that more than 770 million users visited SNS in July 2009, and SNS reached almost $70 \%$ of the total global online audience (Nguyen, 2010). In USA, 73\% of wired American teens and $47 \%$ of online adults use SNS (Lenhart et al., 2010). Approximately $24 \%$ of the Malaysia population use Facebook (Gonzalez et al., 2012). Media Metrix Report stated that $67 \%$ of Malaysian Internet users are SNS users (Nguyen, 2010). According to a new survey conducted by the UK Online Measurement Company (UKOM), the British spend more time on social networks and blogs than any other online activity (Burrows, 2010, cited in Mun, Li \& Fernandez, 2011).

SNS are web-based services providing the functions of creating a public or semipublic profile that displays a list of other users with whom they are linked to (Boyd \& Ellison, 2008). SNS consist of various features such as a profile page, which contains the individual user's personal information like location, education background, status, birthday information, and interests among other things. Other features available on SNS include photograph or image albums, list of connections that they have approved of, wall for posting comments, instant and email messaging options. Users are also able to create and join groups, as well as organize events and make announcements on SNS.

Since the introduction of SNS in 2004, there has been a rapid and dramatic growth of its usage, which has changed the purpose, and functionality of the Internet (Kelly, Kerr \& Drennan, 2010). SNS provide an engaging, interactive platform with a greater control of information flow for their users. SNS are used for developing relationships, disseminating information, expanding social networks, entertainment, etc. Previous research suggested that SNS mainly support preexisting social relations (Boyd \& Ellison, 2008). In addition, research found that SNS are more likely to be used by youth as an avenue for communication and hanging out with friends. Similarly, connecting with friends was found to be the main reason of SNS usage among $91 \%$ of the American teens (Lenhart \& Madden, 2007, cited in Boyd \& Ellison, 2008). Therefore, SNS now serve extensively as a large network for developing relationships and peer-to-peer communication.

The use of SNS among youth is related to the attitude towards SNS. Although past studies have shown a negative attitude towards SNS, the majority viewed SNS favorably (Hirst et al., 2012). Recently, those who see it as a golden opportunity to reach their target market have adopted SNS as a new medium for advertising. Although past studies generally indicated a negative attitude towards advertising (Wang et al., 2002), the attitude towards advertising on SNS should be reevaluated since it is a new medium consisting of novel and interactive applications. Eun and Kim (2009) argued that consumers' attitude toward Web advertising may not be the same as their attitude toward the Web as a medium itself. Media context have a significant influence on the advertising value. The factors affecting attitude toward advertising are "Entertainment", "Informativeness", "Interactivity", "Irritation", "Credibility", and "Demographic" (Wang et al., 2002).

The extensive use of SNS is not only a trend among consumers. Likewise, the increased usage of SNS can be observed in 
many organizations. Many firms such as Whole Food Market, Johnson \& Johnson, and McDonald's are using SNS to increase brand image (Dragger et al., 2010). Professional service firms also utilize SNS as a marketing tool to execute social media marketing plan in order to achieve the firms' goals (Dragger et al., 2010). Thus, advertisers adopting SNS should provide relevant and added value commercial message to their advertisements (Kelly, Kerr \& Drennan, 2010).

The most visited online social network is Facebook, founded in 2004 and with over 600 million users and presence in over 70 countries (Carlson, 2011). Facebook allows users to create a profile of them and explore the profiles of others, gaining an insight into others' lifestyle and interests (Acar \& Polonsky, 2007). In Vietnam, according to Vinalink Media Company (2011), about 53\% Internet users (15 million people) were using at least one social network. Many Facebook users suggested that information shared on SNS were always cared and attracted, especially photos from a journey they had passed. For these reasons, young people are the focus of this study.

SNS are mostly for young consumers. This is a channel for them to interact with others. In the US, college students browse Facebook an average of 10-30 minutes daily (Ellison et al., 2007), responsible for \$200 billion annually in expenditures, or as much as "half the spending in the economy" (Djamasbi et al., 2010). It would be a great channel for the tourism economy to invest. In the context of Tourism Malaysia, the launch of the latest Tourism Malaysia Internet advertising was claimed to reflect the significance of the internet as the most preferred media platform from which travellers can obtain travel information (Yaakop \& Hemsley-Brown, 2013).

In the context of SNS, gender likely affects information dissemination. Gender differences were investigated in various contexts in Information Systems literature such as computer-related attitudes and behaviors (Whitley, 1997); video games (Bilgihan et al., 2014); and e-learning (Gonzalez-Gomez et al., 2012). Although there were no studies investigating such behaviors across genders in relation to tourism, but previous studies reveal that gender differences exist in the use of SNS (Trammel \& Keshelashvili, 2005). To examine consumer characteristics, the theoretical foundations for this study derive from marketing literature: consumer opinion leadership (COL) and consumer susceptibility to interpersonal influence (CSII). These traits likely are important in SNS, because consumers can influence one another in various ways: as role models, as imitators of purchase and consumption behavior, as spreaders of message through word-of-mouth, and as advisors to other consumers with less knowledge or experience with shopping (Flynn et al., 1996).

\section{Literature review and hypotheses}

Web 2.0

The term Web 2.0 or social media was officially defined by O'Reilly (2005) as "the network as platform, spanning all connected devices" and its applications are "those that make the most of the intrinsic advantages of that platform "(O'reilly, 2005). Based on the original definition of O'Reilly, several definitions have been proposed. Hoegg et al. (2006) defined Web 2.0 as "the philosophy of mutually maximizing collective intelligence and added value for each participant by formalized and dynamic information sharing and creation". Andersen (2007) defined this term in two ways: Short description refers to a group of technologies that have become deeply associated with the term: blogs, wikis, podcasts, RSS feeds and so on; technologies contributing to a more socially connected web where everyone is able to add to and edit the content. The long definition is more complicated, touching on economics, 
technology and new ideas about the connected society (Constantinides, Romero \& Boria, 2009). And Nielsen (2008) proposed four components encapsulating what he considers as the Web 2.0 defining elements: Rich internet applications (RIA); community features, social networks, and user-generated content; mashups (using other sites' services as a development platform); and advertising.

Based on these above definitions, Constantinides, Romero and Boria (2009) proposed a detailed illustration of Web 2.0 along three main dimensions: Application types, social effects and enabling Technologies.

\section{Social Networking Sites (SNS)}

According to Boyd and Ellison (2008), SNS are "web based services that allow individuals to construct a public or semipublic profile within a bounded system, articulate a list of other users with whom they share a connection, and view and traverse their list of connections and those made by others within the system". Thus, they emphasized building online connections among people who share interests and activities and provide ways for users to interact. Like Web 2.0, SNS, which is one of Web 2.0's tools, also has many definitions. These are three viewpoints from the perspective of strategy, research and technology companies (Stroud, 2008):

(1) Quarterly McKinsey: "Social networking refers to systems that allow members of a specific site to learn about other members' skills, talents, knowledge or preferences".

(2) Pew/Internet: "A social networking site is an online location where a user can create a profile and build a personal network that connects him or her to other users".

(3) Wikipedia: "A social network service focuses on the building and verification of online social networks for communities of people who share interests and activities, or who are interested in exploring the interests and activities of others. It provides various ways for users to interact - chat, messaging, email, video, file sharing, blogging and discussion groups".

Originally, most SNS were memberbased, Internet communities that allowed users to communicate in innovative ways. Now they are increasingly used in business, creating new channels for consumers to connect with companies and other customers. Companies can easily identify their target customers, then communicate and distribute information to them on SNS. On the other hand, consumers can click "follow", post comments, discuss to other consumers on SNS, and so on. The social communication services provided by SNS in turn affect the company-customer relationship, including brand image and brand awareness (Jansen et al., 2009). According to Zhang et al. (2011), one of the main reasons making Facebook, top used SNS, become an effective tool for marketers is that "it developed several marketing instruments that can directly be employed by companies, including banner advertisements, groups, and fan pages". For example, Facebook allowed Amazon, an American international electronic commerce company; to create an application that Facebook user can write reviews, share with their friends on Facebook and even buy books from Amazon. EBay is talking with both Facebook and MySpace about making it easier for their members to access the auction site (Stroud, 2008).

In order to integrate SNS into the marketing strategies, we should understand its effects on the consumer's decision-making process, and the customer motives for using SNS. According to Constantinides et al. (2009), customer preferences and decisions are increasingly based on inputs provided by parties beyond the control of online 
marketers: peer reviews, referrals, blogs, tagging, social networks, online forums, and so on. In general, with the development of internet and advantages of SNS, marketers can use SNS as a new advertising tool, a channel to manage customer relationship, and empower customers to participate in their marketing activities: branding review, product development, product evaluation, and customer service. This is the basis of a transparent and pleasant.

According to Bilgihan et al. (2014), consumers have information seeking and information sharing behaviors. However, information sharing behavior in Bilgihan et al.'s (2014) scale corresponds to information dissemination of Walsh and Mitchell (2009) view on information sharing. Therefore, the two dimensions used in this study are now labeled as information seeking and information dissemination.

\section{Tourism Destination}

There have been many studies and models of development based around what is referred to as the tourism destination. These studies tend to perceive the tourism destination as a system containing a number of components such as attractions, accommodation, transport, and other services and infrastructure (Tinsley \& Lynch, 2001). Determining a definition of tourism itself is a complex and unresolved issue as Pearce (1989) illustrated in his attempt:

"Tourism has been defined in various ways but may be thought of as the relationships and phenomena arising out of the journeys and temporary stays of people travelling primarily for leisure or recreational purposes. While writers differ on the degree to which other forms of travel (e.g. for business, for health or educational purposes) should be included under tourism there is a growing recognition that tourism constitutes one end of a broad leisure spectrum".

Baggio, Scott and Cooper (2010) defined tourism destinations "were considered as complex systems, represented as a network by enumerating the stakeholders composing it and the linkages that connect them".

While there is a significant literature on the importance of the relationships between tourists and service organizations and connecting tourism companies (Tinsley \& Lynch, 2001), few works are available which examine a tourism destination from a network point of the measurement of tourism destination image has been important for both researchers and practitioners. An accurate assessment of image will help destination marketers design an effective marketing strategy (Baloglu \& Mangaloglu, 2001).

Online social travel networking is also changing the way tourists plan their trips. These websites allow users to interact and provide reviews on hotels or on local tourist attractions. Some examples of these websites are TravBuddy.com, Travellerspoint, WAYN, Woophy, Passportstamp, and TripAdvisor.com. The latter is probably the largest travel community on the Web. It was founded in 2000 and currently covers 212000 hotels, over 30,000 destinations, and 74000 attractions worldwide (Miguéns, Baggio \& Costa, 2008).

\section{Consumer Opinion Leadership}

Consumer Opinion Leadership (COL) has been of interest to marketers for a long time and has been defined in different ways. Originally, It is based on the idea that there are "certain people who are most concerned about the issues and as well as most articulate" (Lazarsfeld et al., 1948). They referred to these people as opinion leaders, and they exert interpersonal influence. Katz and Lazarsfeld (1955) defined opinion leaders as "individuals who are likely to influence other persons in their immediate environment". It can also be regarded as social communication between opinion givers and opinion seekers as interpersonal communication refers to an exchange of information between individuals (King \& 
Summers, 1970).

Merton (1957) made a distinction between those opinion leaders that influence opinions in limited spheres and those opinion leaders who exert interpersonal influence in several different spheres. Previous studies have also examined the characteristics of opinion leaders and addressed their influence on other consumers' purchasing behaviors in various shopping contexts. In a study of opinion leaders in the women's fashion segment, King and Summers (1970) found substantial differences between fashion opinion leaders and non-leaders, using demographic, sociological, attitudinal, communication, and fashion involvement measures. Corey and Erickson (1971) posited that they were "models of opinion who could be influencers on marketing efforts by word of mouth communication to people around them". And most of the literature on opinion leadership relates to interpersonal communication in an offline sphere (Corey, Flynn et al., 1996), with a few studies investigating opinion leadership in an online sphere (Eastman et al., 2002; O'Cass \& Fenech, 2003; Bailey, 2005).

Eastman et al. (2002) focused primarily on insurance sales agents, their use of Internet, also as their attitudes toward the Internet. They developed opinion leadership scores, subjective knowledge scores, for these sales agents using opinion leadership scale of Flynn et al. (1996). Next they compared these scores to attitudes toward the Internet, and found that agents with a higher level of subjective knowledge about the Internet were more likely to be opinion leaders about the Internet. In addition, opinion leaders and agents with higher levels of subjective knowledge had a more favorable attitude about the Internet. However, according to Bailey (2005), they found significance only for the relationship with opinion leadership. Sales agents who were younger than the mean age of 46 years old were more likely to be opinion leaders, and they had a higher level of subjective knowledge of the Internet. Flynn et al. (1996) concluded that perceived knowledge and the willingness to discuss the Internet with others impacted the agents' attitude toward the Internet. They also concluded that younger agents would play a major role in how the Internet would be used.

The Technology Acceptance Model (TAM) was used and applied by O'Cass and Fenech (2003) to assess the adoption of Internet for retail usage among a convenience sample of Australian web users. Among the constructs in which they were interested were opinion leadership and its role in impacting web usage. They found that it was one of the antecedents that impacted users' perceptions of the usefulness and ease of use of the Web for retail purchases.

The above studies showed that opinion leadership have an impact on consumers' use of product review websites. Bailey (2005) also made a new definition for opinion leadership in the online domain as "E-opinion leadership" and adapted the offline definition of the construct for the online domain: Consumers' ability to influence other online consumers' opinions (Flynn et al., 1996; Reynolds \& Darden, 1971). E-opinion leaders are more likely than non-E-opinion leaders to give their opinions and the Internet provides a forum for them to dispense these opinions (Bailey, 2005).

Flynn et al. (1996) applied the concept to marketing by stating: "opinion leadership occurs when individuals try to influence the purchasing behavior of other consumers in specific product fields". In the marketing perspective, Hazeldine and Miles (2010) stated that opinion leaders were motivated by seeking and dissemination information with others, and they tended to be more interconnected with their peers than the other segments. Consequently, they can influence other people through interpersonal communication more frequently and effectively. 
As mentioned in above chapter 2.2.2, opinion leaders are a major source of eWOM communication and regarded as valuable information sources because they frequently communicate with others. More than that, they have knowledge and expertise that will guide the decision making of opinion seekers (Bertrandias \& Goldsmith, 2006). They are trusted to be credible as they share both positive and negative information. Selfconfidence has also been shown among the characteristics of opinion leaders because when an individual has self-confidence; there is less need for him or her to seek information from others (Reynolds \& Darden, 1971).

According to Bilgihan, Peng and Kandampully (2014), from a marketing perspective, opinion leaders are characterized by influence, expertise, communication, and interpersonal word of mouth. They are also motivated by seeking and sharing information with others. Therefore, the first hypothesis which is linking COL with young people' tourism destinations information seeking and information dissemination on SNS is formulated as below:

Hla: Consumer opinion leadership (COL) has positive effect on young people's tourism destinations information seeking behavior on SNS.

$H 1 b$ : Consumer opinion leadership (COL) has positive effect on young people's tourism destinations information dissemination behavior on SNS.

\section{Influence}

\section{Consumer Susceptibility to Interpersonal}

Consumer Susceptibility to Interpersonal Influence (CSII) has long been a source of interest for marketers and consumer behavior researchers (Bailey, 2005), usually conceptualized as a general personality trait that varies across individual consumers and relates to other consumer traits or behaviors (Orth, 2005). Bearden et al. (1989) defined CSII as "the need to identify or enhance one's image with significant others through the acquisition and use of products and brands, the willingness to conform to the expectations of others regarding purchase decision, and the tendency to learn about products and services by observing others and/or seeking information from others."

Bearden et al. (1989) argued that CSII constitutes a stable trait that varies across individuals and is related to other traits and characteristics. In order to measure these inter-individual differences, they developed a scale that consisted of two separate dimensions, namely, susceptibility to normative influence (SNI) and susceptibility to informative influence (SII).

Research building on the research of Bearden et al. (1989) has mainly focused on the scale's normative dimension (SNI). Consumers high in SNI have been shown to prefer products with visible social benefits such as style (Batra et al., 2001), to be less skeptical of advertising (Mangleburg et al., 2004), and are more likely to engage in protective self-presentation in consumption situations (Wooten \& Reed, 2004). People possessing this trait tend not to see themselves as autonomous and independent, but rather as individuals who need to connect with and be respected by others. Hence they are easily influenced by the opinions and wish of persuasive others when making decisions, and readily comply with the suggestions of the latter in order to avoid their disapproval (Bearden et al., 1989). Seiler et al. (2013) also stated that SNI is a measure of how easily a person can be swayed to change his position on a certain topic. The more easily a person's opinion can be changed, the faster the disease or cure can spread. Those who have larger social networks are better able to spread the disease or cure simply because they come in contact with more people.

Bearden et al. (1989) defined susceptibility to informative influence (SII) refers to an individual's tendency to ask friends and relatives for advice and to observe what 
brands and products other people are using before making a purchase decision. Hofstede (1984) also noted that relations and friends get better deals than strangers and this is the way it should be. These showed that once a relationship is established between a retailer and a customer, then the retailer could expect a higher loyalty from the customer. Similarly, the customer can expect the service and product quality rendered to be higher than at an unfamiliar outlet. Further, consumer complaint behaviors might be impacted (Milner, Fodness \& Speece, 1993).

Fundamentally, high susceptibility indicates a tendency to be influenced by others when making decisions; low susceptibility indicates more independence in making decision (Clark \& Goldsmith, 2006).

Social influence has been generally recognized as an important force shaping an individual's consumer behavior and these influences may occur prior to purchase (e.g. word of mouth, information seeking). Young people may yield to friends' influence because they possess relevant information. They also tend to provide necessary information to their peers because such behavior helps them construct positive self-identities (Mangleburg et al., 2004). Therefore, we assume that:

$H 2 a$ : Consumer susceptibility to interpersonal influence (CSII) has positive effect on young people's tourism destinations information seeking behavior on SNS.

$H 2 b$ : Consumer susceptibility to interpersonal influence (CSII) has positive effect on young people's tourism destinations information dissemination behavior on SNS.

\section{Gender Differences}

Previous studies revealed that gender differences exist in the use of SNS (Trammel \& Keshelashvili, 2005). Schler et al. (2005) stated that female bloggers use more words than males. Nowson and Oberlander (2006) found that females put more effort into posting online content than males. For example, females tend to self-disclose more to their good friends (Caldwell \& Peplau, 1982), change the level of self-disclosure more depending on the intimacy of relationships, are more sociable and sensitive, have more intimate social networks, are more actively involved in intimate conversation (Walker, 1994), are more motivated to create and maintain relationships by the avoidance of isolation (Tannen, 1992), and to form more socio-emotion-oriented social networks (Karweit \& Hansell, 1983) than males. Tannen (1992) expounded in her book "You Just Don't Understand" that women and men fail to understand each other because they speak in different language codes and listen with different priorities. She stressed that the differences needed to be revealed and understood so that communication between the sexes could be improved.

Females would also form more stable relationships than males, because socioemotion-oriented networks develop emotional bonds that build solid relationships (Hirschi, 1969). In contrast, males are more likely to spend time in common activities (Walker, 1994), to communicate with the purpose of gaining and maintaining social position (Tannen, 1992), and prefer task-oriented social networks (Karweit \& Hansell, 1983). These results indicate that females tend to be more interested in personal and emotional communication, and in building more stable relationships than males. Some studies have also found that females have more extensive social networks (Walker, 1994), suggesting that females' friendship behavior within their social networks may be more active than males'. More recently, Lu et al. (2010) stated that information sharing behavior or information dissemination behavior is influenced by gender.

Such gender differences have already been found in computer-mediated communication. For example, females use PC e-mail to communicate about private matters more than males, and are more satisfied with 
communication via PC e-mail, and are more likely to utilize it to build intimate relationships (McKenna, Green \& Gleason, 2002). Therefore, we would expect that females will have more personal, more emotionally involved, and more stable friendships, and expand their social networking site when compared with males. The hypothesis is formulated as below:

H3a: The impact of COL and CSII on young people's tourism destinations information seeking behavior on SNS will be strongly influenced by gender.

$H 3 b$ : The impact of COL and CSII on young people's tourism destinations information dissemination behavior on SNS will be strongly influenced by gender.

Based on the above studies, a model is proposed. Details about model and its hypotheses as follows.

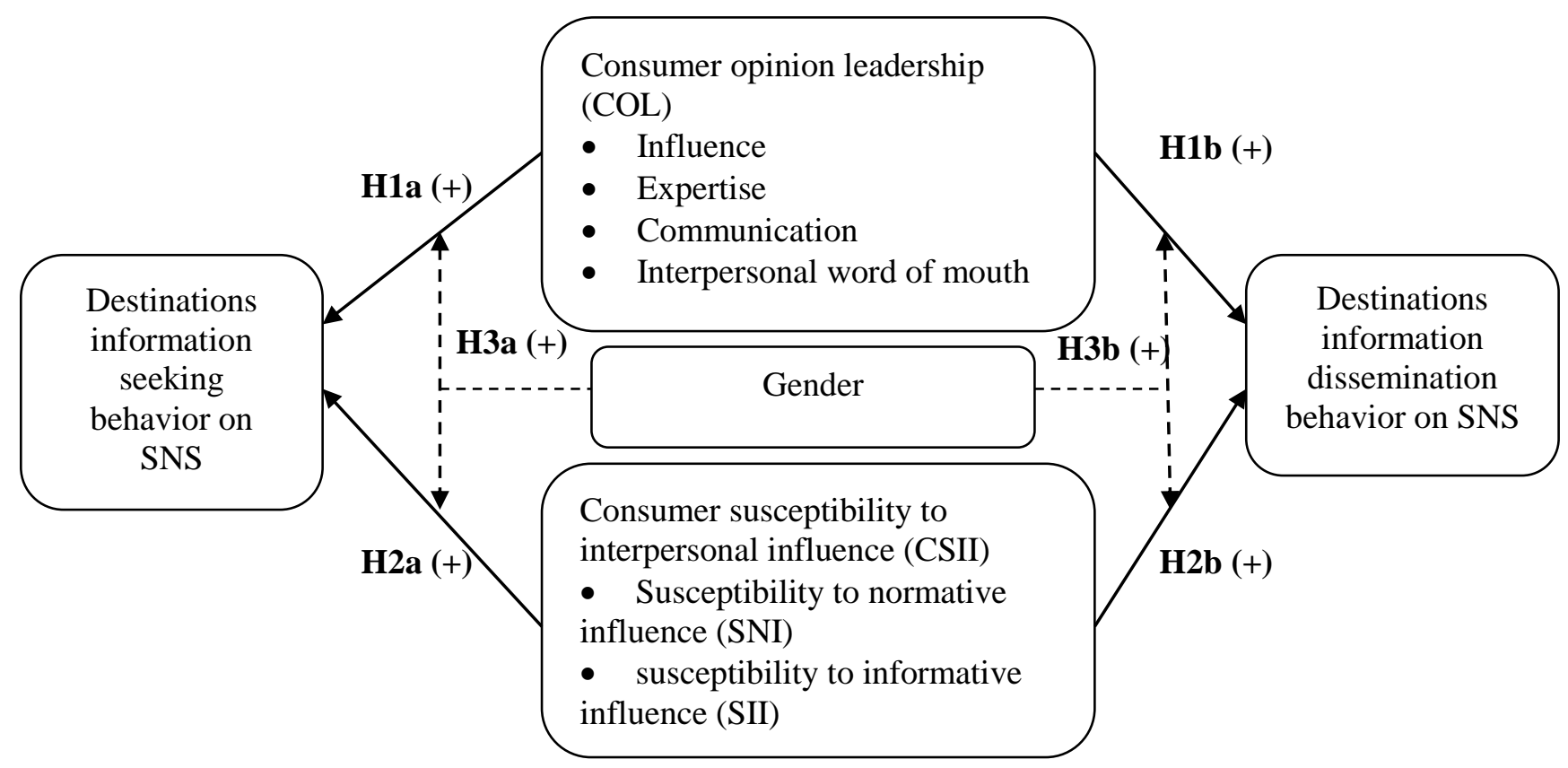

Figure 1. Research Model

\section{Research method}

\section{The Design and Sample}

The model and hypotheses were tested from a self-administered survey conducted among young people, from teens to people in their early 35, who usually use SNS in Vietnam. A total of 350 questionnaire forms were sent to respondents by email and directly on the SNS websites. The 202 usable questionnaires collected represented a response rate of $57 \%$.

All the variables were measured using scales adapted from previous research studies. A three-section questionnaire was developed to detail tourism destinations information seeking and dissemination behavior on SNS of the respondents. The first section asked participants to report their age, their gender and whether they use SNS or not, what SNS they use. The second section included six questions about participants' use of SNS and tourism destinations information seeking and dissemination behaviors. The third section included seven questions to measure COL and CSII. These items were used by Bilgihan, Peng and Kandampully (2014), reflected insights from the broad literature review, involving studies of SNS (Bilgihan et al., 2011; Zhang et al., 2011) and information seeking and dissemination behavior (Kiel \& Leyton, 1981).

To measure COL, this study adapted a scale developed by Reynolds \& Darden (1971): 
Table 1. COL scale

\begin{tabular}{cl}
\hline No. & \multicolumn{1}{c}{ Item } \\
\hline 1 & My friends and family often ask my advice about some tourism destination. \\
2 & I sometimes influence my friends' choices tourism destination. \\
3 & $\begin{array}{l}\text { My friends come to me more often than I go to them for information about tourism } \\
\text { destination. }\end{array}$ \\
4 & $\begin{array}{l}\text { I can think of at least two people whom I have told about choosing tourism destination in } \\
\text { the last six months. }\end{array}$ \\
\hline
\end{tabular}

To measure CSII, Bailey (2005) used the four items measured on seven-point scales anchored by Strongly disagree and Strongly agree to measure informational influence, which are also appropriate for measuring consumer behavior on the internet. In terms of the applicability of each item to the tourism destinations information seeking and dissemination behavior context, three of the four items could be retained. Item omitted was "to make sure I buy the right product or brand, I often observe what others are buying and using".

Table 2. CSII scale

No. Item

1 I often consult other people to help choose the best tourism destination

2 If I have little experience with a tourism destination, I often ask my friends about it.

I frequently gather information from friends and family about a tourism destination before I go.

Respondents evaluated the frequency of their use of SNS on a five-point Likert scale for answers $(1=$ "not at all" to $5=$ "very frequently") in the second section and a fivepoint Likert scale for answers (1= "strongly disagree" to $5=$ "strongly agree") in the third section.

Scale items of information seeking and dissemination behaviors were also adapted from Bilgihan, Peng and Kandampully (2014).

Table 3. Scale of Seeking and Dissemination Behaviors

\begin{tabular}{cl}
\hline No. & Item \\
\hline & Information Seeking \\
\hline 1 & Do you "become a fan" of or "like" some tourism pages on SNS? \\
2 & Do you look for tourism destination information on SNS? \\
3 & Do you click on ads of deals and coupons about tourism destination on SNS? \\
& Information Dissemination \\
5 & Do you update status on Facebook about a tourism destination you have been to? \\
6 & Do you check in locations of a tourism destination on SNS? \\
\hline
\end{tabular}


The original questionnaire was in English, and was translated into Vietnamese for respondents unlikely to be sufficient fluent in English. Double-translation technique (Marin \& Marin, 1991) and Back-translation technique (Brislin, 1980) were used to ensure equivalence of meanings. Firstly, the English version of the questionnaire (the Original Language) was translated into Vietnamese (the Target Language) by the author's supervisor. The author then took the Vietnamese version and translated it into the English version without consulting with the supervisor. Next, the author compared the two English versions to make sure that there is no significant difference in meaning from the intended goal of the project and to identify problems with the translations (odd wording, improper meaning, and incomplete sentences). Finally, the author engaged the supervisor in discussions as to what had been done and how to resolve discrepancies.

\section{Analysis and results}

In table 1, it contains some general information about the participants. The 202 respondents included more women $(70.3 \%)$ than men $(29.7 \%)$. The dominant age group was people born between 1989 and 1996 (52.5\%, ages 18-25 years at the time of the study). In terms of SNS use, $86.6 \%$ of the respondents interacted on Facebook, 9.4\% used Google+, $2 \%$ used Zing me, and others were $2 \%$. Facebook is undoubtedly the most popular SNS among respondents at the time of the study.

Table 4. Respondents Demographic

\begin{tabular}{llllll}
\hline \multirow{4}{*}{ Gender } & & Frequency & Percent & Valid Percent & Cumulative Percent \\
& Male & 60 & 29.7 & 29.7 & 29.7 \\
& Female & 142 & 70.3 & 70.3 & 100.0 \\
& Total & 202 & 100.0 & 100.0 & \\
\hline \multirow{4}{*}{ Age } & $18-25$ & 106 & 52.5 & 52.5 & 52.5 \\
& $26-35$ & 95 & 47.0 & 47.0 & 99.5 \\
& 36- 45 & 1 & 0.5 & 0.5 & 100.0 \\
& Total & 202 & 100.0 & 100.0 & \\
\hline \multirow{4}{*}{ SNS } & Facebook & 175 & 86.6 & 86.6 & 86.6 \\
& Google+ & 19 & 9.4 & 9.4 & 96.0 \\
& Zing me & 4 & 2.0 & 2.0 & 98.0 \\
& Others & 4 & 2.0 & 2.0 & 100.0 \\
& Total & 202 & 100.0 & 100.0 & \\
\hline
\end{tabular}

Measurement Assessment

\section{Cronbach's alpha}

The results indicated that all scales which were higher than .6 satisfied the requirement for reliability: 0.678 for tourism destinations information seeking behavior, 0.617 for tourism destinations information dissemination behavior, .749 for COL, and
.709 for CSII. It showed that the internal consistency was acceptable.

\section{Exploratory factor analysis (EFA)}

All the variables were run through the Principal Axis Factor analysis, using the Promax rotation method to reduce the set of observed variables to a smaller, more 
parsimonious set of variables. After rotation of independent variables, the communalities of independent variables were .612 and factor loading of items was higher than .5 satisfied the requirements. The communalities of dependent variables were 2.772 and factor loading of items was higher than .6 also satisfied the requirements. The KMO measure of sampling adequacy was .786 and .808 (higher than .7) indicating a good acceptance (Hutcheson \& Sofroniou, 1999). This means that the variables are correlated highly enough to provide a reasonable basis for factor analysis. Barlett's test having significance level at $\mathrm{p}<.001$ indicated that the data is suitable for factor analysis because the assumption of multivariate normality is met and the correlation matrix is not an identity matrix. Hence this result is acceptable.

Two factors of dependent variables cannot be split after rotation. Results reveal

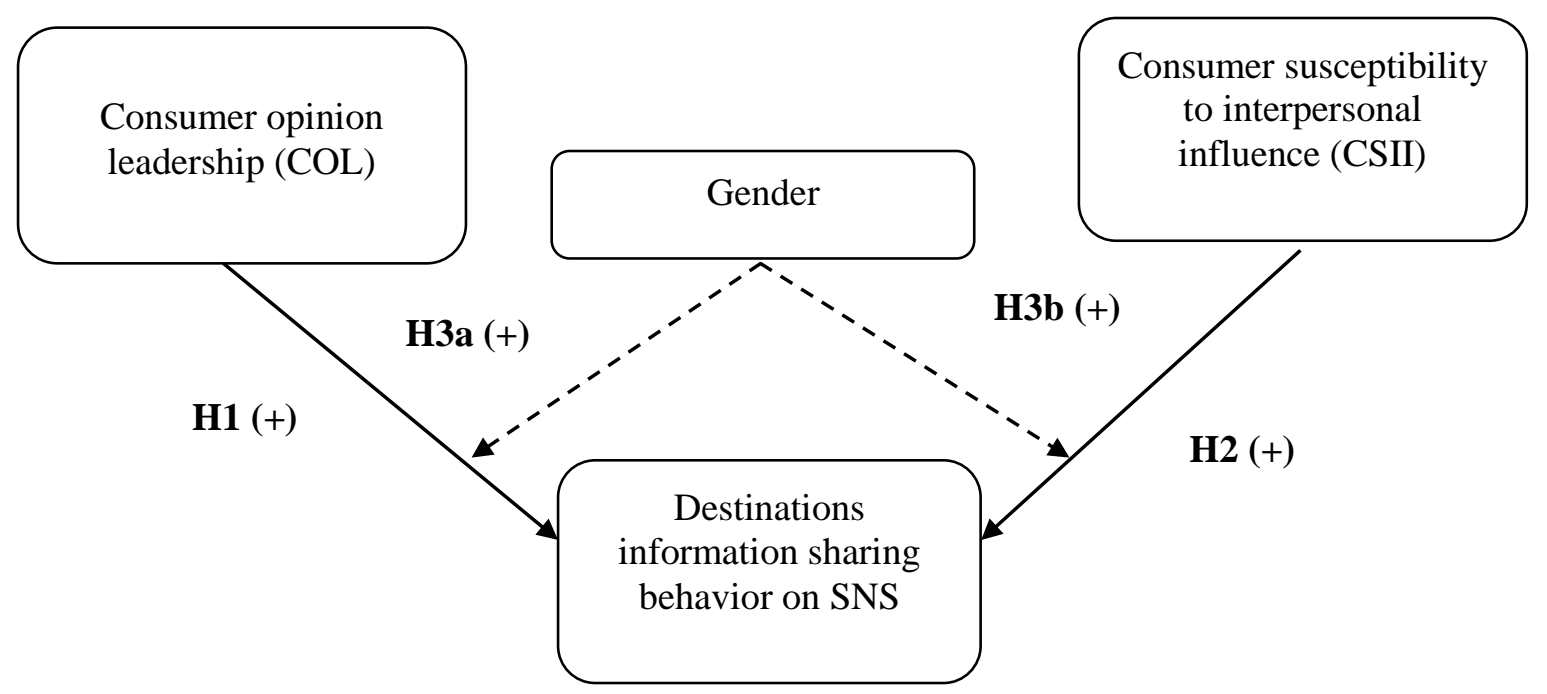

Figure 2. Revised Research Model

Pearson Correlation Coefficient

Table 5. Pearson Correlation Coefficient

\begin{tabular}{llllll}
\hline & & Sharing & Gender & COL & CSII \\
\hline \multirow{2}{*}{ Pearson } & Sharing & 1.000 & & & \\
Correlation & Gender & 0.003 & 1.000 & & \\
& COL & $0.457^{* *}$ & -0.101 & 1.000 & \\
& CSII & $0.493^{* *}$ & -0.054 & $0.550^{* *}$ & 1.000 \\
\hline
\end{tabular}

**. Correlation is significant at the $1 \%$ level (2-tailed). 
The correlations between the independent variables (COL, CSII, and Gender) and dependent variables (Sharing behavior) were tested by using Pearson correlations. Result of Table 4.10 indicated that there was a strong, positive correlation between the variables. Sharing behavior has a significant correlation with both COL $(\mathrm{r}=$ $.457, \mathrm{p}<.001)$ and CSII $(\mathrm{r}=.493, \mathrm{p}<.001)$. Hence, COL and CSII have significant impacts on sharing behavior. Gender doesn't have correlation to other variables. COL and CSII have high correlation with each other $(\mathrm{r}=.550$, $\mathrm{p}<.001$ ). These two variables can be seen that they are measuring two different concepts. So the high correlation between them could be explained as COL also has positive impact on CSII. The correlation matrix of table 2 indicated there are not any correlations above .8 with $\mathrm{p}<.01$. That might be happen weak multicollinearity and supported for the testretest reliability of the variables.

Regression Analysis

The Anova table showed $\mathrm{F}=27.596$ with $\mathrm{p}<.001$ is significant. This indicated that the combination of the predictors significantly predict math achievement. Sig. of COL and CSII was $\mathrm{p}<.001$ at $1 \%$ significance level, thus supporting $\mathrm{H} 1$ and $\mathrm{H} 2$. Sig. of Gender $p>.005$ thus failed to support for $\mathrm{H} 3$.

\section{Discussion, conclusion and limitations}

Discussion and Implications

COL concept in this study, which was applied for tourism, are still consistent with previous researches that associated COL with insurance (Eastman et al., 2002), computer software (Hazeldine \& Miles, 2010), and product review websites (Bailey, 2005). The findings also indicate that young people who are highly susceptible to interpersonal influence tend to share more tourism information on SNS than less susceptible consumers. This finding is consistent with previous studies that linked CSII to review websites usage (Bailey, 2005), wine brand choice (Orth, 2005), drinking and smoking behavior (Kropp et al., 1999).

The results confirmed that young people are heavy users of a wide variety of SNS. It also reflected their attitudes toward SNS as well as their information sharing behavior. These findings highlight the importance of social media marketing. Hence tourist companies and marketers must recognize and exploit the power of social media. They should create their own SNS to help everybody find and engage with them online. On SNS, they also could post the video clips or main information about tourism destinations.

Opinion leaders tend to share more tourism destinations information. Thus, marketing activities and tactics should be engaged to attract opinion leaders. Doing so may result in fan engagement in SNS, so providing one of the fastest and most cost efficient ways to build a significant marketing tool for tourism.

The findings also indicate that young people who are highly susceptible to interpersonal influence tend to share more tourism information on SNS than less susceptible consumers. By associating CSII with SNS usage, this study substantiates the fundamental relationship between CSII and consumer behavior and offers insights into the information seeking and dissemination behaviors of young people. Besides, they can send and receive both positive and negative messages from other SNS users regarding the tourism destination they visited and how they were treated there, how the services are, how they feel and whether they would return again. These messages are likely to influence their tourist decisions and will continue to be heavily relied upon in the future. These would help the marketers get more information and build the strategy to develop the tourism destinations more effectively. Finally, the lack 
of gender difference in information seeking and dissemination behaviors suggested that both man and women attach equal importance to social networking sites.

This study has aimed to raise marketers' awareness of young consumers. And to market successfully to this generation, marketers should realize where these young consumers tend to spend their time and money. The results of this study further confirm that young people are heavily users of Facebook. They seek and share tourism information on SNS at moderate frequency. Additionally, a small proportion of them show very active information sharing behavior. Hence tourism marketers must recognize and exploit the power of SNS, especially Facebook. Marketers should open new channels on Facebook to reach this emerging growth segment. For example, they might build Facebook fan pages to connect with tourists who used their services in the past and post videos or promotions on SNS. The benefits of marketing on Facebook are lower communication costs, personalized and directed advertising, immediate feedback from customers, word-of-mouth referrals and positive influence on consumer behavior.

Ertell (2010) believed that loyal customers want to connect with businesses through social media, but it is how businesses interact with them once they get there that foster greater loyalty and the likelihood to buy in the future. He went on to state that $49 \%$ of customers join to find out about special offers or promotions, while $45 \%$ would like more product information. Hence marketers should give them product information they want without sounding too much like salespersons. Ireson (2010) also suggested the main reason that Facebook marketing will work is because the organization will enter a community and engage as a friend to customers and that Facebook itself is based around the premise of friendship implying trust.
Because Facebook is becoming a new marketing tool for companies to enhance their brand awareness, they need to adopt new marketing policies and strategies that are different from the traditional ones. Marketing teams need to learn new communication strategies about how to maintain and improve long term relationships with existing customers and also how to reach out to other prospective customers (Gil-Or, 2010). Mangold and Faulds (2009) proposed the following to guide interactions in order to have a positive impact on the organization:

(1) Create communities of people who share interests.

(2) Engage customers using social networking tools such as blogs.

(3) Appeal to a range of customers by combining marketing tools.

(4) Disseminate product information.

(5) Give customers a notion of exclusivity regarding certain products.

(6) Create products that make customers converse with each other and the organization.

(7) Appeal to the customer's affinity with causes.

(8) Create memories through storytelling.

(9) Think outside the square and challenge extremes.

It also is critical to understand consumers' online information sharing behavior. The results show that COL and CSII applying to tourism sector can explain sharing information behavior of young people on SNS.

\section{Limitation and Future Research}

Considering the exploratory nature of this study, it contributes to a greater appreciation of the importance of studying young consumers. As is the case for most exploratory studies, the generalizability of these results is limited. The sample used for this study consisted of young people in Vietnam. This study was founded only on customers from one nation, thus the study 
cannot be generalized to tourists from other nations. Additional studies should recruit more participants, spanning the entire range of the notion and age. On the other hand, the study ignored other elements that might change the results such as region, geographical location, social class, education level and so on.

Data of this study is cross-sectional data. The survey was conducted in 2014, one specific point in time. Hence the results for one time period are to be assumed valid at some different point in time. In this study, respondents cannot answer questions involving past events such as frequency of uploading photos, sharing tourism information on SNS with perfect accuracy. This either magnifies or minimizes the effects of certain variables, affecting the cross-sectional study's results.

This study centers on consumer behavior and confirms the importance of social media marketing. People seek and share opinions online, just as they do offline, which affects the sales of products and services (Goldsmith and Horowitz, 2006). Therefore, additional studies should examine social media from a corporate angle. For example, they might consider the return on investments in social media. Such extended examinations of social media marketing can offer additional insights to increase understanding of this growing area of interest in the restaurant industry.

From tourism marketer view point, enabling online or physical social sharing environments where consumers can boost their self confidence may help to diffuse the information on a faster pace. However, it is difficult for them to identify opinion leaders and consider them as a market segment. In order to target and influence opinion leaders and to motivate positive word of mouth communication, marketers need to understand the motivations and circumstances why opinion leaders engage in information sharing. The results can also provide guidance for future studies that aim to better understand the motives for sharing information and opinions on SNS. For example, Facebook can be considered as an example where consumers boost their self-confidence through sharing information. They constantly post in their Facebook wall what they do, where they have been, their desires and dislikes and more. Trying to enhance self-confidence has been found in this study as one of the major motivations of opinion leadership.

Besides, future research may look at the innovative dimension in order to examine if the motivations differ. Conflicts might exist concerning the proximity of opinion leaders with the people they influence. Some participants stressed opinion leaders to be similar to them in terms of values, beliefs, and social status, but some others thought that opinion leaders should have a different view so that they will provide a different, richer perspective. Hence future research should investigate whether opinion leaders are similar or not to the people they influence.

This study has only examined customer behavior on SNS and tourist sector that are significantly different when compared to other contexts. It would be interesting to examine the generalizability of the model and whether the findings could be replicated to other contexts and different types of businesses other than the tourist industry. Future research could exam other consumer behaviors on SNS or information sharing behavior relating to fashion, restaurant, vehicles and so on.

The structural model might be applied to other sectors, rather than just tourism, to validate the model and make further refinements on the structural model to show whether the findings of this study hold true or not. Bearing in mind that the measures used in the current study in the tourist context cannot be adapted exactly to measure the constructs 
of interest in another context, some constructs would be irrelevant. Furthermore, some of the results of this study were unexpected, e.g. the gender differences were not supported in this study but might be supported in other contexts. Therefore, future research could investigate this issue further.

This study was based on one nationality of respondents. Therefore, the study cannot be generalized to the whole population of tourists, neither in Vietnam nor in other countries. Future studies should be conducted with respondents from other nationalities or cultures to confirm whether the model still provides the same results and to make further improvements on the theoretical model.

\section{Conclusion}

The research problem focuses on the relationships between young people's behaviors and explores what are the antecedents of tourism destinations information sharing behaviors of them within the context of SNS. Opinion leaders tend to seek and share more tourism information than non-leaders. This study also adds to our understanding of why young consumers share information on SNS. The results show that young people who are highly susceptible to interpersonal influence tend to share more tourism information on SNS than others. Besides, the lack of gender difference in information sharing behavior suggests that both young man and woman attach equal importance to SNS when it comes to tourism information sharing behaviors. This study focuses on consumer behaviors and confirms the importance of social media marketing. People seek and share opinions online, just as they do offline, which affects the sales of products and services (Goldsmith \& Horowitz, 2006). Hence SNS does not replace the traditional marketing tools but can be used as a complement to existing traditional promotional tools.

\section{REFERENCES}

Acar, A. S., \& Polonsky, M. (2007). Online social networks and insights into marketing communications. Journal of Internet Commerce, 6(4), 55-72.

Andersen, P. (2007). What is Web 2.0?: ideas, technologies and implications for education (Vol. 1, No. 1). Bristol, UK: JISC.

Baggio, R., Scott, N., \& Cooper, C. (2010). Network science: A review focused on tourism. Annals of Tourism Research, 37(3), 802-827.

Bailey, A.A. (2005). Consumer awareness and use of product review websites. Journal of Interactive Advertising, 6(1), 90-108.

Baloglu, S., \& Mangaloglu, M. (2001). Tourism destination images of Turkey, Egypt, Greece, and Italy as perceived by US-based tour operators and travel agents. Tourism management, 22(1),1-9.

Bearden, W. O., Netemeyer, R. G., \& Teel, J. E. (1989). Measurement of consumer susceptibility to interpersonal influence. Journal of consumer research, 473-481.

Bilgihan, A., Nusair, K., \& Okumus, F. (2011). Social Networking Websites: Do Generation Y Use Them Before Making Decisions for Hotels and Restaurants?. 
Bilgihan, A., Peng, C., \& Kandampully, J. (2014). Generation Y's dining information seeking and sharing behavior on social networking sites: An exploratory study. International Journal of Contemporary Hospitality Management, 26(3), 349-366.

Boyd, D.M. \& Ellison, N. B. (2008). Social network sites: Definition, history, and scholarship. Journal of Computer? Mediated Communication, 13(1), 210-230.

Brislin, R. W. (1980). Translation and content analysis of oral and written material. Handbook of cross-cultural psychology, 2(2), 349-444.

Caldwell, M. A., \& Peplau, L. A. (1982). Sex differences in same-sex friendship.Sex Roles, 8(7), 721-732.

Carlson, N. (2011). Facebook has more than 600 million users, Goldman tells clients. Business Insider, 5, 2011.

Clark, R. A., \& Goldsmith, R. E. (2006). Interpersonal influence and consumer innovativeness. International Journal of Consumer Studies, 30(1), 34-43.

Constantinides, E., Romero, C. L., \& Boria, M. A. G. (2009). Social media: a new frontier for retailers?. In European Retail Research (pp. 1-28). Gabler.

Corey, E. J., \& Erickson, B. W. (1971). Oxidative hydrolysis of 1, 3-dithiane derivatives to carbonyl compounds using N-halosuccinimide reagents. The Journal of Organic Chemistry, 36(23), 3553-3560.

Djamasbi, S., Siegel, M., \& Tullis, T. (2010). Generation Y, web design, and eye tracking. International Journal of Human-Computer Studies, 68(5), 307-323.

Dragger, L. F., Lopes, H. F., Maki-Nunes, C., Trombetta, I. C., Toschi-Dias, E., Alves, M. J. N., ... \& Lorenzi-Filho, G. (2010). The impact of obstructive sleep apnea on metabolic and inflammatory markers in consecutive patients with metabolic syndrome. PLoS One, 5(8), e12065.

Eastman, J. K., E.astman, A. D. \& Eastman, K. L. (2002), "Insurance Sales Agents and the Internet: The Relationship between Opinion Leadership, Subjective Knowledge, and Internet Attitudes," Journal of Marketing Management, 18 (April), 259-285.

Ellison, N. B., Steinfield, C., \& Lampe, C. (2007). The benefits of Facebook "friends:" Social capital and college students' use of online social network sites. Journal of ComputerMediated Communication, 12(4), 1143-1168.

Ertell, K. (2010). The Key to Driving Retail Success in the UK with Social Media: Focus on Facebook.

Eun, H. Y., \& Kim, H. S. (2009, October). An affectability consumer's attitudes toward advertising based interactive installation in public transportation,'. InProceedings of the International Association Society of Design Research Conference (pp. 18-22).

Flynn, L. R., Goldsmith, R. E., \& Eastman, J. K. (1996). Opinion leaders and opinion seekers: two new measurement scales. Journal of the Academy of Marketing Science, 24(2), 137-147.

Gil-Or, O. (2010). Building consumer demand by using viral marketing tactics within an online social network. Advances in Management. 
Goldsmith, R. E., \& Horowitz, D. (2006). Measuring motivations for online opinion seeking. Journal of interactive advertising, 6(2), 2-14.

Gordon, L. A., Loeb, M. P., \& Lucyshyn, W. (2003). Sharing information on computer systems security: An economic analysis.Journal of Accounting and Public Policy, 22(6), 461-485.

Gonzalez-Gomez, F., Guardiola, J., Martín Rodríguez, Ó., \& Montero Alonso, M. Á. (2012). Gender differences in e-learning satisfaction. Computers \& Education, 58(1), 283-290.

Hazeldine, M. F., \& Miles, M. P. (2010). An exploratory role analysis of opinion leaders, adopters, and communicative adopters with a dynamically continuous innovation. Journal of Applied Business Research (JABR), 26(4).

Hirschi, T. (1969). Causes of delinquency. Berkeley: University of California Press.

Hirst, A., Bednall, D., Ashwin, M., \& Icoz, O. (2012). The use and abuse of online social network sites by Gen Y in the EU: Can marketing make a difference?. In ICBME 2009: Proceedings of the 5th International Conference on Business, Management and Economics. Yasar University.

Hoegg, R., Martignoni, R., Meckel, M., \& Stanoevska-Slabeva, K. (2006). Overview of business models for Web 2.0 communities. Proceedings of GeNeMe, 2006, 23-37.

Hofstede, G. (1984). The cultural relativity of the quality of life concept. Academy of Management review, 9(3), 389-398.

Jansen, B. J., Zhang, M., Sobel, K., \& Chowdury, A. (2009). Twitter power: Tweets as electronic word of mouth. Journal of the American society for information science and technology, 60(11), 2169-2188.

Karweit, N., \& Hansell, S. (1983). Sex differences in adolescent relationships: Friendship and status. Friends in school: Patterns of selection and influence in secondary schools, 115130.

Katz, E., \& Lazarsfeld, P. (1955). Personal influence.

Kelly, L., Kerr, G., \& Drennan, J. (2010). Avoidance of advertising in social networking sites: The teenage perspective. Journal of Interactive Advertising, 10(2), 16-27.

Kiel, G. C., \& Layton, R. A. (1981). Dimensions of consumer information seeking behavior. Journal of marketing Research, 233-239.

King, C. W., \& Summers, J. O. (1970). Overlap of opinion leadership across consumer product categories. Journal of Marketing Research, 43-50.

Lazarsfeld, P. F., Berelson, B. \& Gaudet, H. (1948), The People's Choice: How the Voter Makes up His Mind in a Presidential Campaign, New York, N.Y.: Columbia University Press.

Lenhart, A., Purcell, K., Smith, A., \& Zickuhr, K. (2010). Social Media \& Mobile Internet Use among Teens and Young Adults. Millennials. Pew Internet \& American Life Project. Retrieved from http://pewinternet.org/Reports/2010/Social-Media-and-Young-Adults.aspx.

Mangleburg, T. F., Doney, P. M., \& Bristol, T. (2004). Shopping with friends and teens' susceptibility to peer influence. Journal of Retailing, 80(2), 101-116. 
Mangold, W. G., \& Faulds, D. J. (2009). Social media: The new hybrid element of the promotion mix. Business horizons, 52(4), 357-365.

Marin, G., \& Marin, B. V. (1991). Research with Hispanic populations. Sage Publications, Inc.

McKenna, K. Y., Green, A. S., \& Gleason, M. E. (2002). Relationship formation on the Internet: What's the big attraction?. Journal of social issues, 58(1), 9-31.

Merton, R. K. (1957). Priorities in scientific discovery: a chapter in the sociology of science. American sociological review, 635-659.

Miguéns, J., Baggio, R., \& Costa, C. (2008). Social media and tourism destinations: TripAdvisor case study. Advances in Tourism Research, (Aveiro).

Milner, L. M., Fodness, D., \& Speece, M. W. (1993). Hofstede's research on cross-cultural work-related values: implications for consumer behavior.European advances in consumer research, 1, 70-76.

Nguyen, J. (2010). The state of social networks in Asia Pacific, with a focus on Malaysia.

Singapore: ComScore.

Nielsen, S. S. (2008). Transitions in diagnostic tests used for detection of $<\mathrm{i}>$ Mycobacterium avium $\langle/ \mathrm{i}\rangle$ subsp. $<$ i $>$ paratuberculosis $\langle/ \mathrm{i}\rangle$ infections in cattle.Veterinary microbiology, 132(3), 274-282.

Nowson, S., \& Oberlander, J. (2006, March). The Identity of Bloggers: Openness and Gender in Personal Weblogs. In AAAI Spring Symposium: Computational Approaches to Analyzing Weblogs (pp. 163-167).

O'cass, A., \& Fenech, T. (2003). Web retailing adoption: exploring the nature of internet users web retailing behaviour. Journal of Retailing and Consumer services, 10(2), 81-94.

O'reilly, T. (2005). Web 2.0: compact definition. Message posted to http://radar. oreilly. com/archives/2005/10/web_20_compact_definition. html.

Orth, U. (2005). Consumer personality and other factors in situational brand choice variation. The Journal of Brand Management, 13(2), 115-133.

Reynolds, F. D., \& Darden, W. R. (1971). Mutually adaptive effects of interpersonal communication. Journal of Marketing Research (JMR), 8(4), 449-454.

Schler, J., Koppel, M., Argamon, S., \& Pennebaker, J. (2005). Effects of Age and Gender on Blogging.

Seiler, M. J., Collins, A. J., \& Fefferman, N. H. (2013). Strategic Mortgage Default in the Context of a Social Network: An Epidemiological Approach. Journal of Real Estate Research, 35(4), 445-475.

Stroud, N. J. (2008). Media use and political predispositions: Revisiting the concept of selective exposure. Political Behavior, 30(3), 341-366.

Tannen, D. (1992). Talking voices: Repetition, dialogue, and imagery in conversational discourse (Vol. 6). Cambridge University Press. 
Tinsley, R., \& Lynch, P. (2001). Small tourism business networks and destination development. International Journal of Hospitality Management, 20(4), 367-378.

Vinalink Media. (2011). Social media in Vietnam. Internet: http://www.slideshare.net/vinalink/social-media-in-vietnam-2011

Walker, K. (1994). I'm no friends the way she's friends': Ideological and behavioral constructions of masculinity in men's friendships. Masculinities, 2(2), 38-55.

Walsh, G., \& Mitchell, V. W. (2009). Identifying, segmenting and profiling online communicators in an internet music context. International Journal of Internet Marketing and Advertising, 6(1), 41-64.

Wang, C., Zhang, P., Choi, R., \& D’Eredita, M. (2002). Understanding consumers attitude toward advertising. AMCIS 2002 Proceedings, 158.

Whitley Jr, B. E. (1997). Gender differences in computer-related attitudes and behavior: A metaanalysis. Computers in Human Behavior, 13(1), 1-22.

Wong, F. M., Lean, M. L., \& Fernandez, P. R. (2010). Social life connects the world: Malaysian youth's usage behaviour of social network sites

Wooten, D. B., \& Reed, I. I. A. (2004). Playing it safe: Susceptibility to normative influence and protective self-presentation. Journal of Consumer Research, 31(3), 551-556.

Yaakop, A., \& Hemsley-Brown, J. (2013). Hedonic Pleasure and Social Image: The Effectiveness of Internet Advertising. Asian Social Science, 9(1), 179-192.

Zhang, L., Mattila, A. S., \& Cranage, D. A. (2011). Become a Fan: A Conceptual Model for Social Media Marketing. Graduate Student Research Conference in Hospitality and Tourism. 